\title{
A Survey of Commercially Available and Proven Remote Control Machines for Excavation and Recovery of Buried Ordnance
}

\author{
C. Pruneda, A. Bilstrom
}

U.S. Department of Energy

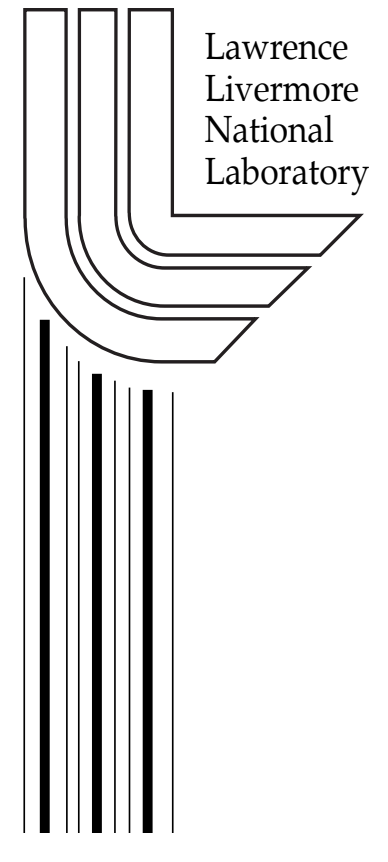

March 1, 2002 


\section{DISCLAIMER}

This document was prepared as an account of work sponsored by an agency of the United States Government. Neither the United States Government nor the University of California nor any of their employees, makes any warranty, express or implied, or assumes any legal liability or responsibility for the accuracy, completeness, or usefulness of any information, apparatus, product, or process disclosed, or represents that its use would not infringe privately owned rights. Reference herein to any specific commercial product, process, or service by trade name, trademark, manufacturer, or otherwise, does not necessarily constitute or imply its endorsement, recommendation, or favoring by the United States Government or the University of California. The views and opinions of authors expressed herein do not necessarily state or reflect those of the United States Government or the University of California, and shall not be used for advertising or product endorsement purposes.

This is a preprint of a paper intended for publication in a journal or proceedings. Since changes may be made before publication, this preprint is made available with the understanding that it will not be cited or reproduced without the permission of the author.

This report has been reproduced directly from the best available copy.

Available electronically at http://www.doc.gov/bridge

Available for a processing fee to U.S. Department of Energy

And its contractors in paper from

U.S. Department of Energy

Office of Scientific and Technical Information

P.O. Box 62

Oak Ridge, TN 37831-0062

Telephone: (865) 576-8401

Facsimile: (865) 576-5728

E-mail: reports@adonis.osti.gov

Available for the sale to the public from

U.S. Department of Commerce

National Technical Information Service

5285 Port Royal Road

Springfield, VA 22161

Telephone: (800) 553-6847

Facsimile: (703) 605-6900

E-mail: orders@ntis.fedworld.gov

Online ordering: http://www.ntis.gov/ordering.htm

OR

Lawrence Livermore National Laboratory

Technical Information Department's Digital Library

http://www.llnl.gov/tid/Library.html 


\title{
A Survey of Commercially Available and Proven Remote Control Machines for Excavation and Recovery of Buried Ordnance
}

\author{
César Pruneda \\ Lawrence Livermore National Laboratory \\ 7000 East Ave \\ Livermore, CA 94550
}

Aaron Bilstrom

Racke Strategies and Technologies, Inc.

4175 SW Humphrey Blvd.

Portland, OR 97221

March 2002

Revision-1 


\section{Table of Contents}

Introduction $\quad \mathbf{3}$

Project Requirements 3

Report on Remote Robotics

Gross / Gantry Robotic Platforms 4

Fine Robotic Systems / Manipulator Mechanisms 5

Soil Removal Systems 6

Sensor Systems 9

Software 11

Preliminary Summary $\quad 12$ 
Principal Investigators: César O. Pruneda

Phone: 925 422-0460

Fax: 925 423-9014

Email: pruneda1@1lnl.gov

Aaron Bilstrom

Phone: 503 225-1950

Fax: $503274-2322$

Email: bilstrom@racke.net

\section{Introduction}

The issue of unexploded ordnance excavation and removal is complicated by the interaction between the independent robotics systems (e.g. manipulator, sensors, and software). A review of commercially available robotic systems highlights the specificity of the design and intent of each for the application and problem being addressed. Although multiple parties, including universities, research institutes, and manufacturers worldwide are concerned with removing explosive ordnance (EOD) and unexploded ordnance (UXO), the exact details of the problems and tasks at each site differ between projects, even slightly. The risks associated with the excavation and removal of ordnance require a level of robustness that necessitates extensive testing and engineering despite project similarities. Based on the experience of researchers, the integration of systems at unique excavation sites will be the critical element of the project to ensure the safe and robust removal of buried ordnance. Although this report touches on some systems integration issues to a limited degree, the report at this stage is primarily a survey of commercially available, proven robotics components and systems for the excavation and recovery of buried ordnance.

\section{Project Requirements}

The overriding requirement concerning the excavation and recovery of buried ordnance at excavation and removal sites is the seamless integration of multiple distinct robotic systems. To facilitate the selection of the most appropriate set of robotic components, the report divides the excavation and recovery tasks into the following categories: gross / gantry robotic platforms, fine robotic systems / manipulator mechanisms, soil removal systems, sensor systems, and software. Although the precision and quality of each element is important, the quality and robustness of the overall system should remain the primary consideration when selecting components. 


\title{
A Survey of Commercially Available and Proven Remote Control Machines for Excavation and Recovery of Buried Ordnance
}

This report will review the relevant remote robotic systems concerned with excavation and recovery. The proven systems included in this report may require modification to function as desired at unique excavation and recovery sites. Because customization of the individual systems will be required to integrate properly, the report may also include some experimental or demonstration systems to provide the reader with a more thorough understanding of the existing options. The defined Task 1 elements discussed in this preliminary report version are indicated below.

\author{
- Review and comment on PMC's plans for robotic systems \\ $\square \quad$ Concepts for the robotic systems \\ Manipulator functions and shapes \\ $\bar{\nabla}$ Concepts for automatic control \\ $\checkmark \quad$ Methods to remove the soil to expose munitions \\ - Mechanical and electrical design criteria for the robotic system elements \\ - Methods to handle munitions with fuses \\ - Recommendations on the recovery sequence of buried ordnance based on \\ risk assessment judgements \\ - Automated path planning issues \\ $\square$ Methods to detect the location of ordnance and to generate signals to control \\ the robotic system to pick up selected ordnance
}

The final version of the report will discuss the above elements including the possible application of available remote robotics technologies and identification of the subsequent steps necessary to implement solutions.

\section{Gross / Gantry Robotic Platforms}

The tradeoff between robot accuracy and range has prompted the division of the recovery task into gross and fine movement robots. The gantry robot is expected to hoist the manipulator mechanism to excavate and remove buried ordnance from burial site. The specialization required of gantry robots for performance at a burial site environment is less sensitive than the manipulators. The Fanuc robot pictured below represents a typical gantry robot that may be adapted to a burial site environment. However, the system chosen will need to be reviewed to ensure the system is capable of withstanding an explosion of ordnance, without compromising the integrity of the overall system. 


\section{Fanuc M-410i}

Fanuc manufactures complete lines of robotics intended for manufacturing and warehouse environments. The M-410i product line, designed for palletizing, depalletizing and order picking, has a maximum reach of 3.13 meters and a payload range of $100 \mathrm{~kg}-400 \mathrm{~kg}$ depending on the model selected.

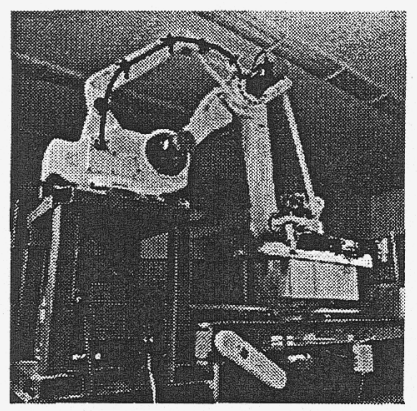

\section{Fine Robotic Systems / Manipulator Mechanisms}

The fine / manipulator robotic system will be responsible for positioning the gripper to extract the munitions from the soil. The selected system will have to integrate with the gripper mechanisms being considered by the PMC (i.e. Mitsubishi Heavy Industries (MHI) and Komatsu) and be adaptable to the risks associated with buried ordnance environments. The commercial market for manipulators is primarily designed for manufacturing, which requires repeating a single type of action or suite of actions thousands of times with exacting precision. Manufacturing robots have low payload capacity relative to their weight. Based on the experience of Sandia personnel, no manufacturing robot can be used off-the-shelf without additional programming, to adapt the robot to the distinct operating environments at ordnance burial sites. Further technical and engineering evaluation of candidate robotic systems will be required to determine suitability to ordnance burial site environments and the modifications necessary to integrate the robotic manipulator into the overall system. Robotic manipulators designed for use in nuclear environments could potentially apply to ordnance burial sites; although they are designed for extreme environments, they may not be suitable for a buried ordnance environment. Another category of manipulators with potential application to the buried ordnance environment are those robotic manipulators designed for undersea use; they are relatively light-weight and quite durable given the extremes of their operating environment. Customization will likely be required of whichever manipulator(s) is selected; even manipulator systems designed for buried ordnance may still require modification to optimize them for the unique burial sites of interest to PMC. The systems featured below may be applicable to buried ordnance sites, pending further review.

\section{Redzone Robotics Dual Arm Work Module}

The Dual Arm Work Module is a device designed to allow two manipulators to work in unison on a single task. The platform allows two off-the-shelf manipulators to be mounted side by side; the orientation and spacing of the manipulators can be varied based on the requirements of the task being performed. The system includes an integral control enclosure and hydraulic power supply that are modular, permitting a

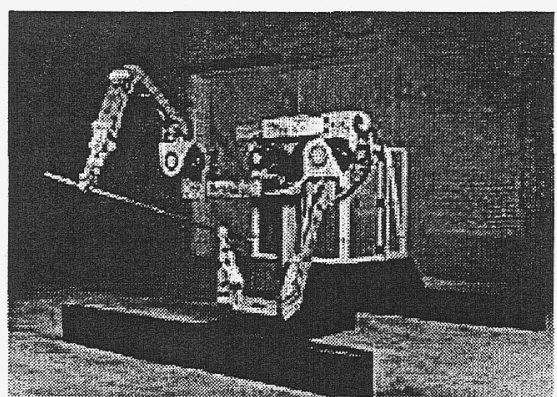


variety of deployable configurations using an overhead crane, mobile vehicle or other platform.

\section{Central Research Laboratories (CRL) Telemanipulator}

The CRL Telemanipulator was designed for nuclear applications. CRL also offers SAMSIN@ (Servo Actuated Manipulator System with Intelligent Networks), a general-purpose electric servo telemanipulator designed for work in remote, hazardous locations. The SAMSIN® lacks autonomous control; instead the operator works from a safe site to perform tasks in a hostile environment, using controls that mirror the arrangement of the telemanipulator.

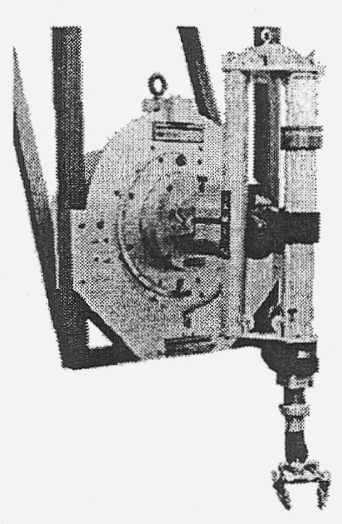

Schilling Robotics Manipulators

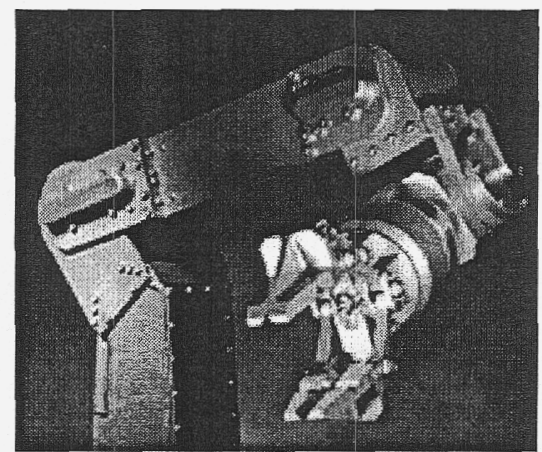

Schilling Robotics, an Alstom company, manufacturers a variety of manipulators for offshore oil, scientific, telecommunications, and military operations. The Titan 3 (featured at right), designed for subsea operations, is constructed primarily of titanium and features a range of 1.915 meters and a payload capacity of $113 \mathrm{~kg}$ at full extension.

\section{Oceaneering}

Oceaneering is another firm specializing in robotic manipulators designed for extreme environments including undersea and nuclear operations. The picture at right features a system designed for work within a nuclear contaminated facility.

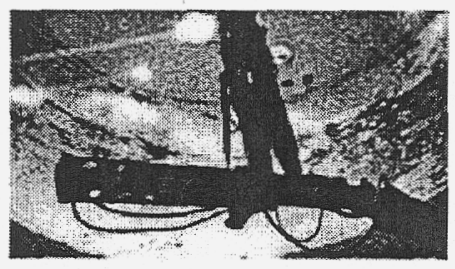

\section{Soil Removal Systems}

In 1994, the U.S. Army initiated Phase I of the Unexploded Ordnance Advanced Technology Demonstration Program with the objectives of, "identifying and evaluating commercial, prototype, and operational technologies for UXO detection, identification, 
and remediation; establishing a technology performance baseline; and understanding the performance of current UXO clearance technology." "The [Phase I] demonstration results also identified areas that require further research and development."2 During Phase I, a total of 29 tests, four of which were multimodal, were conducted between April and October 1994. During Phase II, 15 UXO detection systems and 2 remediation systems were demonstrated between May and September 1995, following procedures similar to Phase I. The tests were conducted at a 120 -acre controlled test site at the U.S. Army Jefferson Proving Ground (JPG) in Madison, Indiana. The program, composed of 4 Phases, was open to any all interested parties, foreign and domestic.

During the remediation portion of Phase I, Benthos, Inc. (a teleoperated controlled excavator/backhoe), Sandia National Laboratories' Remote Telerobotic Vehicle for Intelligent Remediation (RETRVIR), and Tyndall AFB Wright Laboratory's Autonomous Ordnance Excavator (AOE) (Caterpillar 325 long reach excavator) remediated ordinance in the field. During the remediation portion of Phase II, Wright Laboratory tested a distinct system called Remote Excavation Vehicle System (REVS) (excavator system with a Balderson thumb) and Concept Engineering Group (CEG) demonstrated a soft trencher that utilized supersonic air jets and vacuum to recover ordnances; utilization of air-jet technology was unique to both Phase I and II. The CEG trencher excavated 14 targets, including $81 \mathrm{~mm}, 105 \mathrm{~mm}, 106 \mathrm{~mm}, 152 \mathrm{~mm}, 155 \mathrm{~mm}$, and $175 \mathrm{~mm}$ and 8 " projectiles and a 250 -pound bomb, in 18.5 of the 24 hours allotted for its demonstration. During Phase III, Lockheed Martin Advanced Environmental Systems demonstrated a Caterpillar 320L Low Ground Pressure (LGP) excavator with a single remote operator control station (OCS) and OAO Corporation (OAO) demonstrated the Teleoperated Ordnance Disposal System (TODS). The TODS excavated 24 targets during its 40-hour demonstration period. During Phase IV, CEG, the only remediation participant, demonstrated its SAFEX JR system, the basis for its current SAFEX supersonic air jet products. In the final report, it was noted that, "CEG demonstrated a field worthy and safe system of uncovering buried ordnance that minimizes disturbance of the UXO."3

The OAO TODS system was developed for and tested by the U.S. Department of Defense Humanitarian Demining Research and Development Program. OAO Robotics utilized an existing industrial platform and modified it, like many of the systems tested during the Program's 4 Phases, for the specific application of UXO remediation in the field. On December 7, 2001, Lockheed Martin Corporation acquired OAO and has decided to integrate it with Lockheed Martin's Information Support Services. It is unknown how Lockheed Martin will integrate OAO's robotics operations.

\footnotetext{
${ }^{1}$ U.S. Army Unexploded Ordnance Advanced Technology Demonstration Program at Jefferson Proving Ground (Phase II) Report No. SFIM-AEC-ET-CR-96170, pg. ES-2 (http://aec.army.mil/usaec/technology/jpgphaseii.pdf)

${ }^{2}$ Ibid

${ }^{3}$ U.S. Army UXO Technology Demonstration Program at Jefferson Proving Ground (Phase IV) Report No. SFIM-AEC-ET-CR-99051, pg. 4-36 (http://aec.army.mil/usaec/technology/jpgphaseiv.pdf)
} 


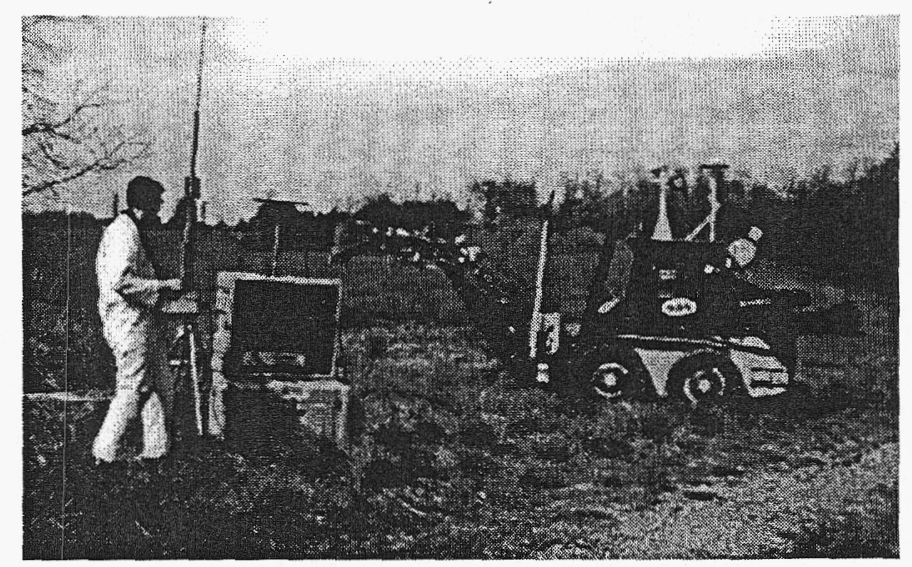

OAO TODS

Concept Engineering Group (CEG), Inc. has applied its patented "Air-Spade" supersonic air jet product concept to its SAFEX products, which are skid-mounted, self-contained air excavators. In 1995, CEG demonstrated its capabilities using an air-based product that would ultimately lead to the SAFEX product, for remediation of unexploded ordnance for the U.S. Army, under Phase II of the Unexploded Ordnance Advanced Technology Demonstration Program. Following that successful test at Jefferson Proving Ground, CEG delivered its system to Tyndall Air Force Base in 1997 to safely uncover buried artillery shells and aerial bombs at the base's military firing ranges. In November 1998, CEG participated in Phase IV of the Controlled Site Advanced Technology

Demonstration Program for UXO removal at Jefferson Proving Ground, using the SAFEX® unit it had developed for the US Army CECOM. CEG offers the SAFEX® 30 (primarily military version), 60, and 150 .

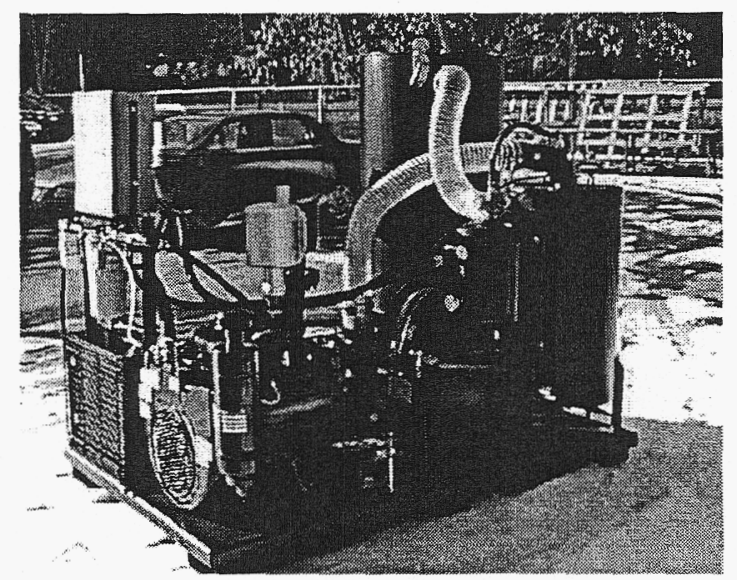

CEG SAFEX® 60

The commercial market includes both air and water-based excavator systems. Additional research concerning water-based excavators is necessary to determine if the water poses a ground water contamination concern. The political sensitivity of the ground water issue may obviate the need for further consideration of water-based systems. Beyond contamination concerns, utilizing water to excavate necessitates stronger vacuum systems 
to address the additional mass, which may impact system robustness. Most commercial air-based products are intended for the utility market and have not been subjected to UXO testing. Angel Guard Products offers a handheld excavation system called Supersonic Air Shovel. Another comparable product is available from Acorn Industries. The issue of adaptability for such commercial products to a UXO environment limits the number of systems for evaluation consideration. System evaluation should concentrate on those systems designed for UXO environments, such as those demonstrated during the U.S. Army's UXO testing from 1994 to 1998.

\section{Sensor Systems}

The Unexploded Ordnance Advanced Technology Demonstration Program at Jefferson Proving Ground (JPG) tested airborne and ground systems to detect and identify unexploded ordnance amongst non-ordnance and debris over 80 and 40-acre areas respectively. The tested systems included Ground Penetrating Radar (GPR), Magnetometer, Infrared (IR), Electromagnetic (EM) and software technologies. In consideration of the PMC's desire for portable sensing units that can be attached to robotic systems, only the man-portable systems will be reviewed here. During Phase I of the trials, systems from Chemrad, Arete Engineering Technologies Corporation, Australian Defence Industries (ADI), Geo-Centers, Inc., UXB International, Inc., EODT Services, Inc., GeoRadar, Inc., Foerster Instruments, Inc., Metratek, Dynamic Systems, Inc., Geometrics, Inc. were evaluated. Despite the significant differences between the testing conditions at JPG and the Haerbaling pits, the technologies utilized by the participants remains applicable.

\section{Phase I Man-Portable System Performance}

\begin{tabular}{|l|c|c|c|c|c|c|c|}
\hline & Platform 1 & $\begin{array}{c}\text { Sensor } \\
\text { Type 2 }\end{array}$ & $\begin{array}{c}\text { Overall } \\
\text { Detection } \\
\text { Ratio }\end{array}$ & $\begin{array}{c}\text { Ordnance } \\
\text { Detection } \\
\text { Ratio }\end{array}$ & $\begin{array}{c}\text { False } \\
\text { Positive } \\
\text { Ratio }\end{array}$ & $\begin{array}{c}\text { False } \\
\text { Negative } \\
\text { Ratio }\end{array}$ & $\begin{array}{c}\text { Search } \\
\text { Coverage }\end{array}$ \\
\hline ADI - 31 & $\mathrm{H} / \mathrm{V}$ & $\mathrm{M}$ & $48 \%$ & $46 \%$ & $92 \%$ & $74 \%$ & $100 \%$ \\
\hline Geo-Centers - 1 & $\mathrm{H} / \mathrm{V}$ & $\mathrm{M}$ & $47 \%$ & $44 \%$ & $100 \%$ & $76 \%$ & $100 \%$ \\
\hline UXB - 13 & $\mathrm{H}$ & $\mathrm{M}$ & $43 \%$ & $36 \%$ & $* *$ & $* *$ & $70 \%$ \\
\hline Foerster - 44 & $\mathrm{H}$ & $\mathrm{M}$ & $41 \%$ & $37 \%$ & $100 \%$ & $89 \%$ & $52 \%$ \\
\hline Dynamic Systems 36 & $\mathrm{H}$ & $\mathrm{M}$ & $28 \%$ & $27 \%$ & $* *$ & $* *$ & $100 \%$ \\
\hline CHEMRAD (G822-L) - 7 & $\mathrm{H} / \mathrm{V}$ & $\mathrm{M} / \mathrm{G}$ & $25 \%$ & $31 \%$ & $*$ & $90 \%$ & $11 \%$ \\
\hline METRATEK - 33 & $\mathrm{H}$ & $\mathrm{M}$ & $23 \%$ & $24 \%$ & $100 \%$ & $74 \%$ & $83 \%$ \\
\hline Geometrics - 43 & $\mathrm{H}$ & $\mathrm{M}$ & $17 \%$ & $16 \%$ & $89 \%$ & $67 \%$ & $55 \%$ \\
\hline ARETE - 19 & $\mathrm{H}$ & $\mathrm{G}$ & $14 \%$ & $20 \%$ & $*$ & $96 \%$ & $4 \%$ \\
\hline GeoRadar - 42 & $\mathrm{H}$ & $\mathrm{M}$ & $7 \%$ & $7 \%$ & $*$ & $87 \%$ & $24 \%$ \\
\hline EODT - 25 & $\mathrm{H}$ & $\mathrm{M}$ & $5 \%$ & $4 \%$ & $100 \%$ & $97 \%$ & $100 \%$ \\
\hline CHEMRAD (GSM-19) - 6 & & $\mathrm{H}$ & $29 \%$ & $*$ & $65 \%$ & $12 \%$ \\
\hline
\end{tabular}

1 Transport Mode, $\mathrm{V}=$ Vehicular/Towed, $\mathrm{H}=$ Handheld/Manportable/Man-towed, $\mathrm{H} / \mathrm{V}=\mathrm{Multimodal}$

$2 \mathrm{G}=\mathrm{GPR}, \mathrm{M}=$ Magnetometer (Active \& Passive), $\mathrm{M} / \mathrm{G}=$ Multi-Sensor

* Demonstrator did not discriminate between ordnance and non-ordnance targets

\footnotetext{
${ }^{4}$ U.S. Army Unexploded Ordnance Advanced Technology Demonstration Program at Jefferson Proving Ground (Phase I) Report No. SFIM-AEC-ET-CR-94120, Table 3, pg. 33 (http://aec.army.mil/usaec/technology/jpgphasei-a.pdf)
} 
** Demonstrator declared all targets as ordnance

Phase II Man-Portable System Performance ${ }^{5}$

\begin{tabular}{|l|l|c|c|c|c|c|c|c|}
\hline & $\begin{array}{l}\text { Sensor } \\
\text { Type }\end{array}$ & $\begin{array}{c}\text { Detection } \\
\text { Probability } \\
\mathbf{P}_{\mathrm{n}}(\mathbf{O r d})\end{array}$ & $\begin{array}{c}\text { Probability } \\
\text { False Alarm } \\
\left(\mathbf{P}_{\mathrm{FA}}\right)\end{array}$ & $\mathbf{P}_{\text {random }}$ & $\begin{array}{c}\text { Horizontal } \\
\text { (Radial) } \\
(\mathbf{m})\end{array}$ & $\begin{array}{c}\text { Localization } \\
\text { Vertical } \\
\text { (Depth]) (m) }\end{array}$ & $\begin{array}{c}\text { Vertical } \\
\text { (Mean) } \\
(\mathbf{m})\end{array}$ & $\begin{array}{c}\text { False } \\
\text { Alarm } \\
\text { Ratio }\end{array}$ \\
\hline Parsons & EM & 0.85 & 0.04 & 0.05 & 0.79 & 0.72 & -0.24 & 4.68 \\
\hline Geometrics & MAG & 0.83 & 0.03 & 0.04 & 0.65 & 0.62 & 0.21 & 3.96 \\
\hline Geo-Centers & MAG \& EM & 0.72 & 0.11 & 0.1 & 0.81 & 0.88 & -0.26 & 20.7 \\
\hline Geophex & MAG \& EM & 0.71 & 0.02 & 0.03 & 0.91 & 0.62 & 0.13 & 3.41 \\
\hline ADI (MAG and EM) & MAG \& EM & 0.65 & 0.04 & 0.05 & 0.74 & 0.68 & 0.12 & 9.35 \\
\hline ADI (MAG) & MAG & 0.63 & 0.04 & 0.04 & 0.74 & 0.68 & 0.14 & 8.88 \\
\hline Bristol & EM & 0.62 & 0.05 & 0.05 & 1.04 & 0.97 & -0.66 & 6.97 \\
\hline Vallon & MAG & 0.57 & 0.28 & 0.25 & 0.83 & 0.98 & 0.02 & 68.5 \\
\hline Scintrex & MAG & 0.5 & 0.06 & 0.06 & 0.94 & 0.87 & 0.39 & 10.1 \\
\hline GeoPotential & EM & 0.11 & 0.02 & 0.02 & 1.3 & 0.8 & -0.38 & 13 \\
\hline
\end{tabular}

$\mathrm{MAG}=$ Magnetometer, $\mathrm{EM}=$ Electromagnetic, $\mathrm{GPR}=$ Ground-Penetrating Radar

Phases III (September 1996 - November 1997) and IV (April - November 1998) of the Program concentrated on ordnance detection, which had improved significantly since Phase I, and false-positive readings, which remained an issue with all demonstrated systems. No demonstrator met the U.S. Army's target performance of greater than $75 \%$ effective discrimination of comparable-sized non-UXO (clutter) targets. Phase III results and participants are listed in the table below.

Phase III Detection and Identification System Performance ${ }^{6}$

\begin{tabular}{|l|l|c|c|c|}
\hline & \multicolumn{1}{|c|}{ Sensor Type } & $\begin{array}{c}\text { Detection } \\
\text { Probability } \\
\left(\mathbf{P}_{\mathrm{D}}\right)\end{array}$ & $\begin{array}{c}\text { False Alarm } \\
\text { (FA) Rate } \\
\text { (\#/Hectare) }\end{array}$ & $\begin{array}{c}\text { FA Ratio } \\
\text { (\#/Ordnance } \\
\text { Detected) }\end{array}$ \\
\hline SCA_Geometrics & EM/Grad \& EM/Mag & 0.96 & 41.86 & 3.06 \\
\hline NAEVA & EM/Grad \& EM/Mag & 0.94 & 24.84 & 1.96 \\
\hline GRI (Combined) & EM/Grad \& EM/Mag & 0.93 & 240.53 & 15.23 \\
\hline Geo-Centers & EM/Grad \& EM/Mag & 0.93 & 81.8 & 5.18 \\
\hline Geometrics & EM/Grad \& EM/Mag & 0.9 & 38.44 & 3 \\
\hline GRI (EM) & EM & 0.87 & 123.89 & 8.46 \\
\hline ADI & EM/Grad \& EM/Mag & 0.78 & 109.48 & 8.3 \\
\hline Geophex & EM/Grad \& EM/Mag & 0.77 & 32.44 & 3.11 \\
\hline SCA_Geo-Centers & EM/Grad \& EM/Mag & 0.76 & 43.55 & 3.36 \\
\hline GRI (Mag) & Mag & 0.7 & 223.68 & 18.82 \\
\hline ENSCO & GPR \& EM \& Grad & 0.7 & 48.66 & 5.14 \\
\hline SCA_ADI & EM/Grad \& EM/Mag & 0.63 & 46.8 & 4.36 \\
\hline Foerster & Grad & 0.6 & 36.46 & 4.85 \\
\hline CHEMRAD & EM & 0.5 & 12.9 & 1.91 \\
\hline Rockwell & Mag & 0.34 & 25.93 & 5.7 \\
\hline
\end{tabular}

\footnotetext{
${ }^{5}$ U.S. Army Unexploded Ordnance Advanced Technology Demonstration Program at Jefferson Proving Ground (Phase II) Report No. SFIM-AEC-ET-CR-96170, Table 6-1, pg. 6-2 (http://aec.army.mil/usaec/technology/jpgphaseii.pdf)

${ }^{6}$ U.S. Army UXO Technology Demonstration Program at Jefferson Proving Ground (Phase IV) Report No. SFIM-AEC-ET-CR-99051, Table 1-1, pg. 1-3 (http://aec.army.mil/usaec/technology/jingphaseiv.pdf)
} 


\begin{tabular}{|l|c|c|c|c|} 
Battelle & Mag & 0.12 & 1.71 & 1 \\
\hline GeoPotential & EM & 0.06 & 9.04 & 8.54 \\
\hline Average & & $.68 \pm .28$ & 67.18 & $6.00 \pm 4.77$ \\
\hline
\end{tabular}

The ordnance burial sites of interest to PMC, unlike the JPG testing sites, represent a negligible risk of false-positive detection. A variety of ordnance, (e.g. shells, mortars, bombs) was positioned at the JPG test range. Identification, in addition to simple detection, was required of the participating systems. The table below details the technologies utilized by each participant to both detect munitions and identify the type.

Phase IV Detection and Identification Systems and Technologies ${ }^{7}$

\begin{tabular}{|l|l|l|}
\hline Vendor & Technology & Discrimination Technique* \\
\hline Applied Physics Laboratory & Pulsed Electromagnetic Induction & Statistical Processing \\
\hline NAEVA Geophysics, Inc. & TF Mag., EM-61, EM-61 3D, Protem 47D & Parameter Matching \\
\hline ENSCO, Inc. & Gradiometer, GPR, EM-61HH & Sensor Fusion (matching) \\
\hline Geophex, Ltd. & GEM-3 Multifrequency EM, TF Mag. & Target Match to Signature Library \\
\hline Battelle & GPR & Linear Shape using CNR \\
\hline Sanford, Cohen \& Associates & TF Mag., EM-61HH, GPR & Target Signature Comparison \\
\hline ADV/Alpha Geoscience Pty. Limited & TF Mag., EM-61HH, GPR & Visual Interpretation of GPR \\
\hline Geo-Centers, Inc. & TF Mag., EM-61 & Fuzzy Inference \\
\hline Geophysical Technology Limited & TF Mag., EM. & Statistical Fit to a Data Set \\
\hline Naval Research Laboratory & TF Mag., EM-61 & Physics Based Algorithm \\
\hline
\end{tabular}

TF Mag. - total field magnetometer, GPR - ground penetrating radar, EM-61HH - EM-61 handheld

* from demonstrators' proposals

A majority of the systems tested during the U.S. Army UXO Technology Demonstration Program testing between 1994 and 1998 represent viable detection and identification technologies at burial sites of interest to PMC.

\section{Software}

Software has two important compatibility dimensions (component interface/functionality and human interface) to ensuring the effectiveness and robustness of the overall system. If the mechanical and electronic functionality and capability of the system cannot be fully realized by the software, the performance will suffer. It is understood that the software is expected to function autonomously a majority of the time, but human control will be necessary at times. There are multiple approaches to human tele-manipulation robotic control. Some control mechanisms mirror the setup of the actual robotic system. Two alternative systems can be viewed below. Another alternative is Sandia's own SMART software, which has been applied to Remotec's ANDROS robotic platform to improve the usability of the company's leading EOD robotics. The software selected will need to be adaptable to the hardware platforms selected. Rather than consider the components of the system serially, the selection of both hardware and software components should be considered in parallel to ensure compatibility between systems.

${ }^{7}$ U.S. Army UXO Technology Demonstration Program at Jefferson Proving Ground (Phase IV) Report No. SFIM-AEC-ET-CR-99051, Table 4.1-1, pg. 4-1 (http://aec.army.mil/usaec/technology/jpgphaseiv.pdf) 


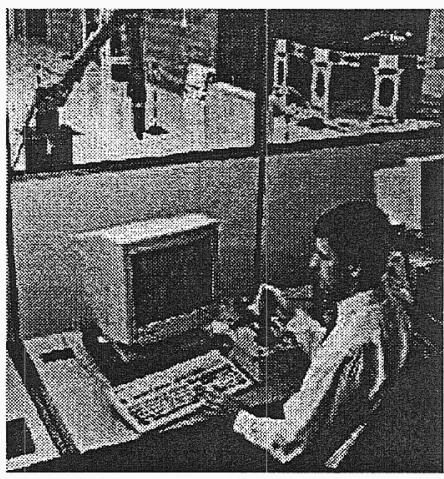

RTS Advanced Robotic's Advanced Teleoperation Controller (ATC)

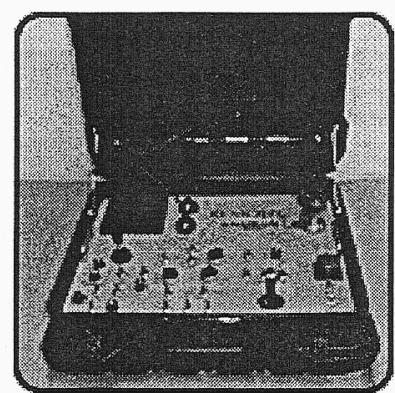

Remotec's ANDROS

Control System

The software system modification / customization for ordnance burial sites will be the most challenging aspect to implementing a robust buried ordnance excavation and removal system. The software platform decision must consider the number of distinct systems involved with the ordnance excavation and removal anticipated at ordnance burial sites. Sandia has developed its own proprietary software platform that improves the human interface to enhance system functionality and reduce training times. The software is called Sandia's Modular Architecture for Robotics and Teleoperation (SMART). SMART is a software tool for building tele-robotic systems from commercial hardware that achieve maximum utility from the hardware, and minimum complexity for the end-user. Features include, but are not limited to: Multi-arm tele-manipulation, Prescribed motion paths, Robot movement in a camera coordinate frame, and Collision avoidance. OAO Robotics' Basic Remote Control System (BARCS) provides a simple and affordable platform to address a variety of remote sensing and manipulation needs. The BARCS can accommodate radio control and teleoperation, manipulators and sensors, including video, IR, GPS, chemical, biological.

The evaluation of potential software platforms will require consultation with experts able to evaluate the capabilities and robustness of the system and ability to accommodate and incorporate the robotic systems being proposed by the PMC.

\section{Preliminary Summary}

The field of robotics offers numerous capable independent systems. However, it is the functioning of overall system that will determine the effectiveness, robustness, safety, and ultimate success of buried ordnance excavation and recovery operations. The interaction between the mechanical, electrical and software systems, and their human operators should be the primary consideration during the design, implementation, and operation of the eventual remote robotic system. The key is to identify those systems or components of the overall robotics plan that require a customized solution and those where an off-the-shelf solution may be sufficient. It is important to remember that all of the existing robotic systems, whether they be manipulators, grippers, sensors were 
designed with a specific application in mind to maximize the effectiveness of the system. While Sandia has utilized multiple robotic systems oriented towards the manufacturing environment, experience has shown that off-the-shelf manipulators require additional customization engineering to function properly in environments such as buried ordnance sites. Despite the extensive engineering resources already invested in the existing systems, to reliably operate in unique ordnance burial sites, subject to the potential risks, will require extensive testing and engineering despite project similarities.

The intent of this report was to outline and describe robotic systems used previously for buried ordnance tasks or with that potential. An informed team is necessary to plan for the contingencies that will impact the safety and quality of the overall system. A list of questions, raised by this exercise, follows this report. To maximize the utility of future activities, it is important to have answers to those questions. Future revisions of this report will delve more deeply into the topics contained within this report. Integration of the respective systems will be discussed in more detail, as well as feedback on the robotic system design decisions being made by the participating parties. 
Table of Relevant Internet Sites and Vendors

\begin{tabular}{|c|c|c|}
\hline Name & Internet Address & $\begin{array}{ll}\text { Page } \\
\#\end{array}$ \\
\hline Barrett Technology, Inc. & http://www.barretttechnology.com/robot/products/prodfram.htm & 19 \\
\hline $\begin{array}{l}\text { British Nuclear Fuels } \\
\text { Limited }\end{array}$ & http://www.bnfl.com/website.nsf/index.htm & 20 \\
\hline $\begin{array}{l}\text { Central Research } \\
\text { Laboratories }\end{array}$ & http://www.centres.com/nuclear/manip/manip.htm & 21 \\
\hline $\begin{array}{l}\text { Concept Engineering } \\
\text { Group (CEG), Inc. }\end{array}$ & http://www.air-spade.com/military uxo.htm & 22 \\
\hline Fanuc Robotics & http://www.fanucrobotics.com/Products/ProductLine.asp & 23,24 \\
\hline $\begin{array}{l}\text { Georgia Tech Mobile } \\
\text { Robot Lab }\end{array}$ & http://www.cc.gatech.edu/ai/robot-lab/ & 25 \\
\hline iRobot & http://www.irobot.com/rd/p09 PrevRes.asp & 26 \\
\hline JPL Robotics & http://robotics.jpl.nasa.gov/ & 27 \\
\hline KfK-Karlsruhe & http://psf-nt-server.fzk.de/Hauptseite framee.htm & 28 \\
\hline LaHague & http://www.cogema-lahague.fr/ & 29 \\
\hline NIST RoboCrane & http://www.isd.mel.nist.gov/documents/ (Large Scale Mfg) & 30 \\
\hline $\begin{array}{l}\text { Oceaneering International } \\
\text { Inc. }\end{array}$ & http://www.oceaneering.com/ (Advanced Technologies) & 31 \\
\hline $\begin{array}{l}\text { OAO Robotics (Lockheed } \\
\text { Martin) }\end{array}$ & http://www.army-technology.com/contractors/mines/oao/ & 32 \\
\hline $\begin{array}{l}\text { ORNL's Robotics and } \\
\text { Process Systems Division }\end{array}$ & http://www.ornl.gov/rpsd/rpsd.html & 33 \\
\hline Redzone Robotics & http://www.redzone.com/pages/ser port-custom.html & 34 \\
\hline $\begin{array}{l}\text { Remotec (Northrop } \\
\text { Grumman) }\end{array}$ & http://www.remotec-andros.com/ & 35 \\
\hline $\begin{array}{l}\text { The Robotics Institute } \\
\text { (Carnegie Mellon) }\end{array}$ & http://www.ri.cmu.edu/ & 36,37 \\
\hline RTS Advanced Robotics & http://www, robotics.co.uk/ & 38 \\
\hline Schilling Robotics & http://www.schilling.com/ & 39,40 \\
\hline $\begin{array}{l}\text { U.S. Air Force Research } \\
\text { Lab Active Range } \\
\text { Clearance (ARC) } \\
\text { Technologies }\end{array}$ & $\begin{array}{l}\text { http://www.uxocoe.brtrc.com/WorkshopNotes/ARC(Waltz- } \\
\text { clark)2.pdf }\end{array}$ & 41 \\
\hline $\begin{array}{l}\text { United States Army } \\
\text { Environmental Center }\end{array}$ & http://aec.army.mil/usaec/ & 42 \\
\hline $\begin{array}{l}\text { U.S. Army Defense } \\
\text { Ammunition Center } \\
\text { (DAC) }\end{array}$ & http://www.dac.army.mil/ & 43 \\
\hline
\end{tabular}




\section{Clarification Details}

The complexity of buried ordnance excavation and demands extensive knowledge of the variables to develop a system that is effective, robust and safe. During the development and creation of this report, the following questions arose. To maximize the utility of future research efforts, inquiry into and answers to the questions is desirable.

\section{Munitions characteristics}

What are the configurations of the munitions, dimensions, weights, intended (design basis) and recommended handling techniques, grasping location and forces, orientations? How much explosive is in the munition and what can it do?

Are all the munition types presently identified?

(Questions leading to machine characteristics)

What could set off a munition?

What are the consequences of a munition firing, physical, political?

What vibrations are of concern, frequency range, and energy level?

Is there any sensitivity to RF?

What levels of acceleration are tolerable (should "slosh-free" movement be used?)

What levels of shock are tolerable?

What could yield the munition casing (crush)?

What are handling temperature limitations?

What materials/compounds should not/cannot be mixed with the chemicals (e.g.

hydraulic oils, solvents, water, etc.)?

What are the consequences of mixing munition components with these

materials/compounds?

\section{Process}

What is the expected recovery sequence?

What limits are there to a manned approach?

How important is it to limit manned approach?

Will temporary structures be built or moved by the manipulators (containment, shielding, etc)?

\section{$\underline{\text { Detect }}$}

What must be detected?

How much resolution is required?

How will the data be processed and used?

What sensors are required?

What deployment requirements do these sensors have (distance from magnetic materials, speed of scan, etc)?

What sensors have physics that may result in degradation, detonation or leakage?

\section{Expose}

How will the excavation be executed?

How deep can the munitions be? 
What is the composition of the overburden?

How will overburden materials be disposed, processed or stored?

Can water sprays be used? Pressure limits?

If the munition is in the water table, will the water be removed?

Will the system be required to operate in or under water?

How deep could water be?

Are there any relevant archaeological methods that can be applied?

\section{Characterize}

Is it important to characterize each munition prior to recovery?

What munition aspects must be characterized and how is this done?

Are the munitions marked to indicate what they are?

What sensors are required (finding, characterizing)?

What sensors have physics that may result in detonation or leakage?

Is it important to weigh the munitions (determine type/content etc)?

Can an EOD database with the munitions be connected to a machine vision system to provide a basis for grasp analysis and path planning?

\section{Recover}

What rate of recovery is required?

How is recovery to be measured (number of munitions, weight, etc.)?

Is there a limit to the number of systems operating simultaneously?

What is this limit?

What dictates this limit?

Can the machines be autonomous? Semi-autonomous? Teleoperation requirement?

Are there any issues with hydraulic oil (contamination, mixed-waste stream, etc)?

What can the chemicals do to machines (seals, booting, metal surfaces, lubricants, copper electrical connections, glass, optical encoders, wire insulation)?

Is contamination to be removed from the munitions prior to packaging or transport?

How is contamination removed from machines, munitions?

How is contamination measured?

How much contamination is too much?

Package

Regarding packaging:

What are the package characteristics?

What dexterity is required to close the package?

Will the package be reopened?

What is total weight?

How will it be handled?

What are the next steps?

\section{Transport}

What interface with recovery systems is necessary? 


\section{Destroy}

Will manipulation be required at the destruction point?

What manipulation will be required (unpacking, loading, etc)?

Is remote sampling or decontamination required post-destruction?

How clean does the munition need to be prior to destruction?

What methods of cleaning are necessary?

\section{Remediate environment}

Will the recovery machines be used for environmental remediation?

What operations will be necessary?

What operations will be required of the recovery machines?

What tools will be required to execute these operations?

What interfaces with the tools will be required?

What dexterity will be required to field the tools?

\section{Waste streams}

Where does the waste material (soil, water, air, etc) go after use, how does it get there? How important are the waste streams (cost, impact, etc)?

What role do the recovery systems play in controlling the waste stream?

\section{Disposition of equipment}

How will the machines be disposed at the end of the project?

Will decontamination be required?

How clean is "clean"?

\section{Infrastructure}

How much volume is available for machinery, work volumes, limitations?

What utilities are available?

What repair facilities are available?

What foundations may be implemented (e.g. concrete footings, rails, etc)?

Is space available for a hydraulic power unit (HPU)?

How will on-site operations be controlled and coordinated?

What information will be required from the manipulator systems at the control point?

How will active systems be connected to control point?

Where will OCU be placed?

What are the climate conditions?

Who will be operating the systems?

\section{$\underline{\text { Regulations and Standards }}$}

\section{Cross-cutting aspects}

What Standards are required for machines, manipulators, and associated equipment?

What environmental standards are applicable?

\section{Previous work/experience}

What work has been done already, who did it, where was it done?

What specific concerns have been identified? 


\section{Responsibilities}

What is the extent of the systems desired from SNL (Assumption: expose and recover)? What is the overall organizational structure, who is responsible for what, contact information?

What is the project approval process?

Who are the project decision-makers?

What companies are interested in working the project in the past and now?

What level of investment did they make?

\section{Reporting}

What reporting is required?

Who reports to whom?

For each report, what is the required:

Content?

Structure?

Frequency?

Recipient?

\section{Scheduling}

What is the master schedule?

Is there flexibility in the schedule?

What are the consequences of early and late accomplishment?

This work was performed under the auspices of the U.S. Department of Energy by the University of California, Lawrence Livermore National Laboratory under Contract No. W-7405-Eng-48. 